\title{
System of key performance indicators as a method for executive decision-making
}

\author{
V. B. Trukhmanov*, E. A. Pervushkina, A. A. Statuev, V.N. Belov, and A.M. Volodin \\ Lobachevsky State University of Nizhny Novgorod, Nizhny Novgorod, Russia
}

\begin{abstract}
Key performance indicators, KPI are a proven cutting-edge tool for process productivity and staff performance monitoring. Therefore, today it is possible to find the use of this tool in the most varied spheres and industries. However, the system implementation is a long and painstaking process, which requires financial, labor and time expenditures. But in case of its successful implementation, KPI technology will provide the balance of advantage for the company management and contribute to its growth. The article presents the selection mechanism of KPI system development and implementation methods. Using key performance indicators, the organization is able to manage the process and modify it, as well as define objectives for employees and motivate them to achieve their objectives. KPIs are based on measuring quantitative benefits. Control shall be based on comprehensive and reliable information about the company's process productivity. This is the only way to take quick management decisions, make adjustments to the operation of processes that will contribute to the achievement of strategic objectives as a whole.
\end{abstract}

\section{Introduction}

KPI (Key Performance Indicators) acronym is increasingly appearing in management books, in articles of well-known magazines, if it comes to efficiency and its measurement. But still there is not much theoretical information on the KPI implementation in organizations at the moment. This definition came to Russia from the West about ten years ago, while at home country it has been used for decades.

Thus, the most famous supporter of management on the basis of measurable objectives is Peter Drucker, who focused on the key performance indicators in his publications [1-5]. He had an opinion that "...you can't manage what you can't measure" [5]. According to this concept, the company's objectives are divided into levels and communicated to employees as targets (KPI). Robert Kaplan also made a great contribution to the KPI development [14, 15]; he wrote many books on a balanced scorecard development and implementation, which includes KPI. In publications he says, "Only when objectives are translated into numbers, they worthy of the name. As long as the objective has no terms and no indicators for evaluating its achievement, it is not an objective, it is a dream".

In article "Strategic management of a large manufacturing outfit" A. Nikitin notes that "...strategic management is a comprehensive system of setting and implementing strategic

\footnotetext{
* Corresponding author: v.truhmanov@yandex.ru
} 
objectives of an enterprise, based on environment forecasting and developing solutions to adapt to its changes, as well as the impact on it" [9].

Efficient management tool that correlates the strategic objectives of an organization with its business processes and the everyday tasks of employees at any level is the Balanced Scorecard (BSC), which is the research result by R. Kaplan and D. Norton [14, 15]. It acts as a point of contact between both financial and other indicators of company's economic activity and identifies causal connection between objectives and key indicators.

It is up to the company's executives to determine strategic objectives and tasks. Implementation of this strategy is the responsibility of corporate business units. Noncommunication of context of the company's strategy to employees, lack of awareness of their unit's role in achieving the objectives set brings to naught the entire process of implementing the company's strategy. Only the awareness of the company's employees and effective management control over the implementation of strategic objectives is the key to the successful achievement of targets.

Strategy implementation control shall be based on comprehensive and reliable information about the company's process productivity. This is the only way to take quick management decisions, make adjustments to the operation of processes that will contribute to the achievement of strategic objectives of the company as a whole.

Risks in the strategy implementation lie in imperfection of information channels between key executives and employees of company. If these channels are not organized effectively, then management decisions will not be based on full and objective information. On the one hand, it may seem that the more information is received by management, the more correct decision will be made. On the other hand, a large amount of data, as a rule, requires longer time to generate reports, and this has a negative impact on the management decision-making process, because of delaying. Moreover, maximum amount of information does not guarantee that the decision will be correct.

The system of key performance indicators, which has long been used by Western companies, can become a tool which simplifying decision-making by the company's management, and now it is becoming increasingly widespread in our country.

KPI system is a breakdown of the company's strategy, it is the basis for an objective assessment of its implementation. Set of key performance indicators is the foundation for an objective assessment and includes characteristics that determine the success factors reflected in the target values of these indicators.

The developed strategy is not a guarantee of achieving the objectives. The main task of executives is to achieve its implementation. It is possible due to setting of clearly defined tasks in the context of structural units and staff, as well as better control over their implementation.

Articulated strategy describes main steps to be taken to achieve the objectives and targeted results. The company's strategy shall be divided into specific strategic initiatives, within which tasks are defined for each structural unit. Essential element of this stage is the prioritization of strategic initiatives and coordination of unit interaction.

Consequently, the KPI system serves principally to assess the effectiveness of staff and informs managers about the current situation of the company as a whole and the contribution of each individual employee in particular, it gives an idea of how the current situation corresponds to the strategic objectives of the company.

\section{Materials and Methods}

Contemporary market requires enterprises to use progressive management methods. To be competitive, enterprises have to develop a strategy, i.e. to draw up a plan for the company development in the long term. Short-term company horizon is the tasks arising from the 
strategy, the implementation of which is assigned to specific units. It is necessary to develop a certain algorithm allowing to correctly formulate the company development strategy, its strategic objectives and properly breakdown them to the level of tasks and practical deeds aimed at their achievement.

One of the methods of management activities, which are the basis of the strategic management, was called management by objectives. Concept of management by objectives was first formulated by Peter Drucker in 1954. In his book "The Essential Drucker" he formulated its basic principles as: "ability to systematize the management process, $<\ldots>$ ability to assess performance of employees, focus on results, $<\ldots>$ and as a consequence, all this leads to higher business performance as a whole" [5].

Thus, the most important principle of system of management by objectives is exactly setting of objectives and tasks, which are broke down from the top down: from the company objectives, to the unit objectives, to the department objectives, and below to the objectives of employee. Units, generating the report on the results of their work according to the established indicators, have the opportunity to compare the results of their unit with the main indicators of company as a whole and evaluate actual effectiveness of the contribution of its unit in achieving overall objectives.

All objectives shall comply with SMART (SMART is a method for describing objectives (tasks), which include: specific, measurable, achievable, relevant to the purpose, timely), the so-called "smart" objectives.

Only this approach to objective setting helps to increase motivation of employees to achieve them. When staff realize the causal connection between their objectives and tasks and the company strategy, then their activities will contribute to the company prosperity.

KPI system allows not only to "digitize" the results of staff activity, but also to assess the contribution of each of them to the company prosperity.

It is wrong to assess the performance of units and staff only by those indicators that can be measured. Yes, when setting the tasks it is necessary to articulate them and give a description on how to measure the results, which is typical for traditional financial and economic indicators, but at the same time to assess degree of implementation of company's strategy other indicators are also needed, a simple mathematical calculation is not always possible and, therefore, measurable. Therefore, a more "balanced" set of indicators of the company's performance, affecting the different company's actions, which would allow to control those factors that affect these indicators, rather than just monitor their performance, is needed.

Methodology of key performance indicators system is a comprehensive approach to organization management, and provides implementation of the company's strategy, allows to understand how the key performance indicators now correspond to the objectives and strategic initiatives in the long term. It is a progressive tool of the company efficiency management.

At the moment there are no universal methodologies of KPI system development, which could be unconditionally applied by any company for developing its own KPI system. There are no recommendations on how to apply few developments that exist in the literature, at Russian enterprises, there is no information on the results of implementation of KPI systems. Various authors, such as A. K. Klochkov [7], Robert Kaplan, David Norton $[14,15]$, G. A. Eremina [6], E. Yu. Dukhonin, D. V. Isaev, E. L. Mostovoy et al. [16] suggest using different development methods in each case, but in general to be guided by the basic principles discussed below. 


\section{Results and Discussion}

Due to the fact that assessment methodology of organizations effectiveness based on KPIs originated in Europe, most often we can explore description of experience in implementing the KPI system in foreign companies. Thus, after analyzing the described experience of KPI system implementation abroad [8,10-13,17-20], it is possible to highlight some more principles relating directly to methodology of development and implementation of the KPI system:

1) principle of regular and timely data collection;

2) principle of simplicity;

3) principle of manager's motivation;

4) principle of keeping the interest.

Let's consider each of them in some detail.

Principle of regular and timely data collection is based on fact that regularly collected information, which objectively reflects the real state of affairs in the company, can provide positive results. For this purpose it is necessary not only to form system of key performance indicators as a set of indicators, but also to determine the rules of data collection, as well as to have software that allows to collect them promptly.

Principle of simplicity implies that the KPI system formulated in the corporate language is understandable to each and every company's employee. It is also important here that the form of reporting, as well as the software for implementation, shall be convenient, simple and approachable for understanding and analysis.

Principle of manager's motivation requires ensuring a high degree of interest of the enterprise's executives both in the development and implementation of the KPI system and in its further functioning.

Principle of keeping the interest, which follows from the previous principle and requires, in order to ensure positive results from the implementation of the KPI system, maintaining interest in it among executives. Only this will increase the effect from its use, thereby improving the company's position in the market, and ensuring its competitiveness.

But in order for the KPI system to be effective, there shall also be absolute confidence that the indicators will be measured on the basis of reliable information reflecting the actual situation. Even if the KPI is strategically important, but it is impossible to measure it, due to the impossibility of obtaining full reliable information on it, such indicator shall either be reviewed and excluded from the system, or the problem of data collection shall be solved. To do this, first of all it is necessary to improve information channels, feedback between management and staff, including employees among themselves.

Each of the above types of KPI systems is a complete system, which can be used in the development and implementation of KPI systems in the companies.

Plan for the KPI system developing may consist of the following stages:

Stage 1. Articulation of the company's vision.

Stage 2. Shaping the company's strategy.

Stage 3. Setting of the company's objectives.

Stage 4. Identification and grouping of company's business processes.

Stage 5. Setting of objectives for business processes.

Stage 6. Development of key performance indicators for each business process.

Stage 7. Accountability of structural units for the company's business processes.

Stage 8. Setting objectives for each structural unit.

Stage 9. Definition of key performance indicators for each unit.

Stage 10. Development of the structural unit performance assessing system, including them in the bonus payment to all employees. 
The existing types of KPI systems were described above. Naturally, the development plan will also depend on the type chosen. Depending on the system's features, the plan includes or excludes certain stages.

The developed KPI system is most often presented in tabular form as the so-called KPI matrix. In fact, the KPI matrix is a table of indicators, which allows to visualize and characterize them by certain parameters in a convenient form for perception and analysis (Fig. 1).

\begin{tabular}{|l|c|c|c|c|c|c|}
\hline \multicolumn{1}{|c|}{ KPI } & \multirow{2}{*}{ Weights } & \multicolumn{4}{c|}{ Values } & \multirow{2}{*}{ KPI index } \\
\hline Sales result, thousand rubles & 0.3 & $\mathbf{1 0 0}$ & $\mathbf{5 0 0}$ & $\mathbf{8 0 0}$ & 600 & $\mathbf{1 2 0 \%}$ \\
\hline Cash inflow, thousand rubles & 0.2 & $\mathbf{1 5 0}$ & $\mathbf{4 0 0}$ & $\mathbf{6 0 0}$ & 300 & $\mathbf{7 5 \%}$ \\
\hline Overdue receivables, thousand rubles & 0.3 & $\mathbf{8 0 0}$ & $\mathbf{3 0 0}$ & $\mathbf{1 0 0}$ & 400 & $\mathbf{7 5 \%}$ \\
\hline Internal customer satisfaction, \% & 0.2 & $\mathbf{0}$ & $\mathbf{8 0}$ & $\mathbf{1 0 0}$ & 90 & $\mathbf{1 1 3 \%}$ \\
\hline & & $\mathbf{1}$ & \multicolumn{3}{|c|}{ Performance ratio (rating) } & $\mathbf{9 6 \%}$ \\
\hline
\end{tabular}

Fig. 1. KPI matrix fragment (example)

Filling in the KPI matrix starts with the entry of KPIs themselves, including SMARTtasks, the solution of which ensures result achievement by the key indicator. Column in which the task weight in the total volume (share from 100\%) is estimated is obligatory, thereby the task priority is defined. "Base", "standard", "objective" columns are designed to enter information about the targeted results. In this case, the base is a value and a decrease below that level is unacceptable; the standard is a result which is mandatory to achieve and, as a rule, it is used in determining the bonus payment percentage as a variable part of salary (the standard corresponds to $100 \%$ of bonus); the objective speaks for itself; it is beyond the objective, which determines the direction of the company in achieving its strategic goals. It is recommended to take a month as a target period.

In addition to the targets, the KPI table displays the results of each task, which in aggregate is the result of the whole key indicator performance. The last table column is the summary rating calculation. Key performance indicators are often the basis of company's motivation system. In this case, the overall rating at the end of month can affect the variable part of employee's salary.

In addition, the matrix may indicate the data sources to fix the actual result, and indicate the persons in whose competence is the results assessment of one or another indicator. In some cases, the KPI matrix may also indicate the possibility of correcting the results of KPI calculation (whether it is possible to correct the indicator to the standard if the indicator is not achieved due to objective reasons).

\section{Conclusions}

KPI matrix is a convenient tool, which clearly, simply and easily reflects the company's objectives, key indicators, unites plans and achieved results, and therefore is an effective method of company management.

KPI system implementation contributes to the growth of staff competence due to the fact that their actions aimed at implementing their strategic objectives are conscious, they understand what have to be improved in the business processes in which they are involved to achieve results.

Indisputable positive moment of KPI system introduction is that on its basis it is possible to build a transparent motivation system, using KPIs as indicators of bonus 
payment. In this case, subjectivity in assessment of staff achievements is excluded and it strengthens the effect of their activity in realization of company strategy.

However, compliance of the KPI system with the above criteria alone does not guarantee the effectiveness of the developed and implemented KPI system. It shall be created not only by the company's executives, but all employees shall take part in the system development. Control and correction shall be carried out by company management, and system developers shall interact with each other.

Within each individual structural unit, key performance indicators can be developed correctly, but if they (units) will develop indicators separately from each other, it will be impossible to establish relationships and cover all company's business processes. In addition, this approach to the KPI system development by a limited group of developers may lead to a large number of indicators in the final version, but for the effective system functioning the indicators shall not be more than a few dozen.

Proper distribution of KPIs over the organizational structure of organization ensures that current activities in each structural unit will be carried out in the right direction, and will contribute to the achievement of company's objectives as a whole.

From all of the above, at present there is no definitive methodology describing the procedure for developing the system of key performance indicators. There is a certain set of requirements, categories, principles, which shall be considered when developing the KPI system. This process is creative, each enterprise has the right to its own way in this direction.

\section{References}

1. P. F. Drucker, Management: tasks, responsibilities, practices (New York: Harper Row, 1974)

2. P. F. Drucker, Management: Tasks, responsibilities and practices (New York: Harper \& Row, 1973)

3. P. F. Drucker, Managing for Results (New York: HarperBusiness, 1993)

4. P. F. Drucker, Management Challenges for the Twenty-First Century (Oxford: Butterworth-Heinemann, 1999)

5. P. F. Drucker, The Essential Drucker (New York: HarperBusiness, 2001)

6. G.A. Eremina, Science Journal, 7(5) (2015)

7. Dmitry Chuprina and partners, http://chuprina.kz/

8. B. Marr, Key Performance indicators (KPI): The 75 measures every manager needs to know (Financial Times Publishing, 2012)

9. Alexander Nikin, Strategic management of a large industrial enterprise, https://www.cfin.ru/

10. D. Parmenter, Key performance indicators: developing, implementing, and using winning KPIs, 3 (Published John Wiley \& Sons, Inc., New York, 2010)

11. H. K. Rampersad, Total Performance Scorecard: redefining management to achieve performance with integrity (Published by Routledge, London and New York, 2003)

12. H. K. Rampersad, Total Quality Management: An Executive Guide to Continuous Improvement (New York: Springer-Verlag, 2001)

13. H. K. Rampersad, K. Tuominen, Total Performance Scorecard: Self-assessment Work Book

14. R.S. Kaplan, D.P. Norton, Harvard Business Review, 70(1), 71 (1992) 
15. R. S. Kaplan, D. P. Norton, The Balanced Scorecard: Translating Strategy into Action (Harvard Business School Press: Boston, MA, 1996)

16. E. Yu. Dukhonin, D. V. Isaev, E. L. Mostovoy, Business performance management. Business Performance Management Concept, 269 (Alpina Business Books, 2005)

17. H. Norreklit, Accounting, Organizations and Society, 28(6), 591 (2003)

18. R. Sparks, Business and Industry Specialist, 10(5) (2001)

19. D. C. Edelman, Harvard Business Review, 62 (2010)

20. S. Einwiller, M. Will, Corporate Communications, 7(2), 100 (2002) 